CARDIOVASCULAR MEDICINE

\title{
Effects of carvedilol on left ventricular remodelling in chronic stable heart failure: a cardiovascular magnetic resonance study
}

\author{
N G Bellenger, K Rajappan, S L Rahman, A Lahiri, U Raval, J Webster, G D Murray, A J S Coats, \\ J G F Cleland, D J Pennell, on behalf of the CHRISTMAS Study Steering Committee and \\ Investigators
}

Heart 2004;90:760-764. doi: 10.1136/hrt.2003.015552

See end of article for authors' affiliations

Correspondence to: Professor Dudley Pennell,

Centre for Advanced MR in Cardiology, Royal Brompton Hospital,

Sydney Street, London

SW3 6NP, UK;

d.pennell@ic.ac.uk

Accepted

25 September 2003
Background: The ability of $\beta$ blockers to improve left ventricular function has been demonstrated, but data on the effects on cardiac remodelling are limited.

Objective: To investigate, using cardiovascular magnetic resonance (CMR), the effects of carvedilol on left ventricular remodelling in patients with chronic stable heart failure and left ventricular systolic dysfunction caused by coronary artery disease.

Design: Randomised, double blind, placebo controlled study.

Setting: Chronic stable heart failure.

Patients and intervention: 34 patients with chronic stable heart failure and left ventricular systolic function taking part in the CHRISTMAS trial (double blind carvedilol $v$ placebo) underwent CMR before randomisation and after six months of treatment.

Main outcome measure: Left ventricular remodelling at six months.

Results: The carvedilol and placebo groups were well balanced at baseline, with no significant intergroup differences. Over the study period, there was a significant reduction in end systolic volume index (ESV) and end diastolic volume index $\left(E D V_{1}\right)$ between the carvedilol and the placebo group (carvedilol $-9 v$ placebo $+3 \mathrm{ml} / \mathrm{m}^{2}, p=0.0004$; carvedilol $-8 v$ placebo $0 \mathrm{ml} / \mathrm{m}^{2}, \mathrm{p}=0.05$ ). The ejection fraction increased significantly between the groups (carvedilol $+3 \% v$ placebo $-2 \%, p=0.003$ ).

Conclusions: Treatment of chronic stable heart failure with carvedilol results in significant improvement in left ventricular volumes and function. These effects might contribute to the benefits of carvedilol on mortality and morbidity in patients with chronic heart failure.
$\mathrm{R}$ ecent years have seen a notable improvement in both morbidity and mortality in patients with chronic heart failure. Much of this benefit is derived from the use of therapeutic agents, including angiotensin converting enzyme (ACE) inhibitors and $\beta$ blockers, which interfere with neurohormonal pathways that are activated by cardiac dysfunction. In placebo controlled trials, $\beta$ blockers have consistently improved survival, reduced hospital admissions, and improved symptoms and quality of life. ${ }^{1-5}$

Much of the benefit of $\beta$ blockade in patients with heart failure secondary to left ventricular systolic dysfunction may result from their ability to improve left ventricular systolic function, which has been demonstrated in various studies using echocardiography or nuclear techniques. ${ }^{6-8}$ Data on cardiac remodelling, however, are limited. Cardiovascular magnetic resonance (CMR) provides an accurate and reproducible measurement of left ventricular remodelling in small sample sizes, by assessment of volumes, ejection fraction, and mass. ${ }^{9}{ }^{10}$ We investigated the effects of carvedilol versus placebo on left ventricular volume, mass, and function using CMR as a measure of cardiac remodelling in patients with chronic stable chronic heart failure and left ventricular systolic dysfunction caused by coronary artery disease. This was a substudy of the CHRISTMAS trial (carvedilol hibernation reversible ischaemia trial; marker of success). ${ }^{11}{ }^{12}$

\section{METHODS}

\section{Patients}

Thirty four consecutive patients recruited for the CHRISTMAS trial from two participating centres were included in the CMR substudy. Patients were recruited between 1995 and 1999, and the study began before publication of the major $\beta$ blocker outcome trials in chronic heart failure. The inclusion and exclusion criteria for the CHRISTMAS trial were as follows:

- chronic stable heart failure (New York Heart Association functional class I-III) from systolic dysfunction caused by coronary artery disease

- already receiving optimised chronic heart failure treatment (including diuretics and an ACE inhibitor if tolerated)

- echocardiographic imaging of sufficient quality for wall motion analysis.

Patients with atrial fibrillation or severe valvar disease were excluded, and additional exclusion criteria for the CMR substudy were the presence of an implanted pacemaker and claustrophobia.

\section{Study design}

Patients underwent the first CMR scan after inclusion in the CHRISTMAS trial, but before randomisation to carvedilol or

\footnotetext{
Abbreviations: CHRISTMAS, carvedilol hibernation reversible ischaemia trial, marker of success; CMR, cardiovascular magnetic resonance; COI, cardiac output index; COMET, carvedilol or metoprolol European trial; $E D V_{1}$, end diastolic volume index; $E F$, ejection fraction; $\mathrm{ESV}_{1}$, end systolic volume index; LVEDV, left ventricular end diastolic volume; LVESV, left ventricular end systolic volume; LVM, left ventricular mass index; $\operatorname{LVSV}_{1}$, left ventricular stroke volume index
} 
placebo. The follow up scan was done six months after randomisation, while patients were still on double blind treatment. Height, weight, and blood pressure were recorded before scanning, the latter done after 20 minutes of rest in a sitting position. During each study, heart rate was recorded continuously and the average heart rate during the scanning sequence noted.

The CMR substudy was approved by the ethics committees of both participating centres, and written consent was obtained.

\section{CMR measurement of remodelling}

CMR was done with a Picker Edge 1.5 T scanner (Marconi, Cleveland, Ohio, USA), using the body coil and ECG triggering, as previously described..$^{13}$ In brief, the cardiac short axis was determined from three scout images of the left ventricle-the transverse axis, the vertical long axis, and the breath hold diastolic horizontal long axis. The basal short axis slice was positioned just forward of the atrioventricular ring, and all subsequent breath hold cines were acquired in $1 \mathrm{~cm}$ steps towards the apex. A breath hold, segmented gradient echo, fast low angle shot (FLASH) sequence was used for each of the contiguous short axis slices. Parameters were as follows: echo time (TE), $3.8 \mathrm{~ms}$; repeat time $(\mathrm{TR})=\mathrm{RR}$ interval; slice thickness, $10 \mathrm{~mm}$; field of view, $35 \times 35 \mathrm{~cm}$; read matrix, 256; phase matrix, 128; frames, 16; flip angle, $35^{\circ}$; phase encode group, 6-10. An average of 10 short axis segments was needed to encompass the entire left ventricle.

Image analysis was carried out on a personal computer using software developed in-house (CMRtools, Cardiovascular Imaging Solutions, London, UK). End diastolic and end systolic images were chosen as the maximum and minimum cross sectional areas in each cine. Short axis end diastolic epicardial and endocardial borders were traced manually for each slice. From the area within the contours and the slice thickness, the epicardial volume and endocardial volume (left ventricular end diastolic volume, LVEDV) were calculated, the difference representing myocardial volume. Left ventricular mass (LVM) was derived from this volume by multiplying by the specific density of the myocardium $\left(1.05 \mathrm{~g} / \mathrm{cm}^{3}\right) .{ }^{14}$ End systolic endocardial borders were also traced, to give left ventricular end systolic volume (LVESV). The dif-

ference between LVEDV and LVESV represents the left ventricular stroke volume (SV). Ejection fraction (EF (\%)) was calculated as $($ LVEDV - LVESV)/LVEDV $\times 100$. Papillary muscles were included in the mass and excluded from the volume. All analyses were done off-line in random order, with investigators blinded to the patient details and previous results.

\section{Statistical analysis}

To control for changes in body mass index over the study period, EDV, ESV, SV, cardiac output (CO), and LVM were expressed as an index of total body surface area-EDV ${ }_{\mathrm{I}}, \mathrm{ESV}_{\mathrm{I}}$, LVSV $_{\mathrm{I}}, \mathrm{CO}_{\mathrm{I}}$, and $\mathrm{LVM}_{\mathrm{I}}$ - by dividing each variable by the patient's body surface area. ${ }^{15}$ Unpaired $t$ tests between the carvedilol and placebo groups were employed at baseline to detect any initial differences. Differences within the carvedilol and placebo groups over the study period were assessed using a paired $t$ test. Differences between the carvedilol and placebo groups over time were examined using an unpaired $t$ test on the intragroup differences. Results are expressed as mean (SD), with a probability value of $p<0.05$ being considered significant. Statistical analyses were done with commercial software (StatView version 4.53; Abacus Concepts Inc, Berkeley, California, USA). The reproducibility of CMR in our centre has been published previously and the interstudy percentage variability is $2.5 \%$ for EDV, $3.1 \%$ for

Table 1 Comparison of ventricular remodelling and haemodynamic variables at baseline and at the end of the study between the carvedilol and placebo groups

\begin{tabular}{|c|c|c|c|c|c|c|c|}
\hline & & Baseline & 6 Months & $\begin{array}{l}\text { p Value, } \\
\text { baseline } \\
\text { differences }\end{array}$ & $\begin{array}{l}\text { Effect over } \\
\text { time }\end{array}$ & $\begin{array}{l}\text { p Value, within group } \\
\text { changes }(95 \% \mathrm{Cl})\end{array}$ & $\begin{array}{l}\text { p Value, between groups } \\
\text { changes over time } \\
(95 \% \mathrm{CI})\end{array}$ \\
\hline LVEDV $\left(\mathrm{ml} / \mathrm{m}^{2}\right)$ & $\begin{array}{l}\text { Carvedilol* } \\
\text { Placebo* }^{*}\end{array}$ & $\begin{array}{l}139(46) \\
130(43)\end{array}$ & $\begin{array}{l}131(46) \\
130(39)\end{array}$ & NS & $\stackrel{\downarrow}{\rightarrow}$ & $\begin{array}{l}0.001 \text { ( } 3.5 \text { to } 12.8) \\
\text { NS ( } 6 \text { to } 7.5)\end{array}$ & 0.05 (-0.3 to 14.6$)$ \\
\hline $\operatorname{LVESV}_{1}\left(\mathrm{ml} / \mathrm{m}^{2}\right)$ & $\begin{array}{l}\text { Carvedilol } \\
\text { Placebo }\end{array}$ & $\begin{array}{l}100(48) \\
89(34)\end{array}$ & $\begin{array}{l}91(45) \\
92(37)\end{array}$ & NS & $\stackrel{\downarrow}{\rightarrow}$ & $\begin{array}{l}0.0004(4.8 \text { to } 13.0) \\
\text { NS }(-7.8 \text { to } 1.7)\end{array}$ & 0.0004 (5.9 to 18.2 ) \\
\hline $\operatorname{LVSV}_{1}\left(\mathrm{ml} / \mathrm{m}^{2}\right)$ & $\begin{array}{l}\text { Carvedilol } \\
\text { Placebo }\end{array}$ & $\begin{array}{l}39(9) \\
41(13)\end{array}$ & $\begin{array}{l}40(7) \\
36(8)\end{array}$ & NS & $\begin{array}{l}\rightarrow \\
\rightarrow\end{array}$ & $\begin{array}{l}\text { NS }(-6.8 \text { to } 3) \\
\text { NS (-1.3 to } 9.6)\end{array}$ & NS \\
\hline LVEF (\%) & $\begin{array}{l}\text { Carvedilol } \\
\text { Placebo }\end{array}$ & $\begin{array}{l}31(13) \\
32(10)\end{array}$ & $\begin{array}{l}34(13) \\
30(10)\end{array}$ & NS & $\stackrel{\uparrow}{\rightarrow}$ & $\begin{array}{l}0.008(-5 \text { to }-0.8 \\
\text { NS ( }-0.6 \text { to } 5.2)\end{array}$ & $0.003(-8.5$ to -1.9$)$ \\
\hline $\operatorname{LVM}\left(\mathrm{g} / \mathrm{m}^{2}\right)$ & $\begin{array}{l}\text { Carvedilol } \\
\text { Placebo }\end{array}$ & $\begin{array}{l}77(23) \\
91(24)\end{array}$ & $\begin{array}{l}77(18) \\
89(29)\end{array}$ & NS & $\rightarrow$ & $\begin{array}{l}\text { NS }(-6.8 \text { to } 8) \\
\text { NS (-5.6 to } 10.9)\end{array}$ & NS \\
\hline Heart rate (beats/min) & $\begin{array}{l}\text { Carvedilol } \\
\text { Placebo }\end{array}$ & $\begin{array}{l}80(13) \\
84(8)\end{array}$ & $\begin{array}{l}74(14) \\
80(12)\end{array}$ & NS & $\begin{array}{l}\rightarrow \\
\rightarrow\end{array}$ & $\begin{array}{l}\text { NS }(-2.2 \text { to } 14.0) \\
\text { NS }(-5 \text { to } 11)\end{array}$ & NS \\
\hline BP systolic (mm Hg) & $\begin{array}{l}\text { Carvedilol } \\
\text { Placebo }\end{array}$ & $\begin{array}{l}121(18) \\
127(20)\end{array}$ & $\begin{array}{l}116(13) \\
121(14)\end{array}$ & NS & $\rightarrow$ & $\begin{array}{l}\text { NS }(-1.2 \text { to } 11) \\
\text { NS (-2.3 to } 15)\end{array}$ & NS \\
\hline BP diastolic $(\mathrm{mm} \mathrm{Hg})$ & $\begin{array}{l}\text { Carvedilol } \\
\text { Placebo }\end{array}$ & $\begin{array}{l}74(13) \\
70(13)\end{array}$ & $\begin{array}{l}73(12) \\
73(9)\end{array}$ & NS & $\begin{array}{l}\rightarrow \\
\rightarrow\end{array}$ & $\begin{array}{l}\text { NS }(-3.0 \text { to } 6.7) \\
\text { NS }(-3.0 \text { to } 14.6)\end{array}$ & NS \\
\hline BSA $\left(\mathrm{m}^{2}\right)$ & $\begin{array}{l}\text { Carvedilol } \\
\text { Placebo }\end{array}$ & $\begin{array}{l}1.8(0.1) \\
1.8(0.2)\end{array}$ & $\begin{array}{l}2.0(0.2) \\
1.8(0.1)\end{array}$ & NS & $\vec{\rightarrow}$ & $\begin{array}{l}\text { NS }(-0.01 \text { to } 0.02) \\
\text { NS }(-0.07 \text { to } 0.02)\end{array}$ & NS \\
\hline
\end{tabular}

Values are mean (SD).

${ }^{*}$ Carvedilol group, $\mathrm{n}=16$; placebo group, $\mathrm{n}=13$.

$B P$, blood pressure; BSA, body surface area; $L_{V E D V}$, left ventricular end diastolic volume index; LVEF, left ventricular ejection fraction; $L V E S V_{1}$, left ventricular end systolic volume index; LVM, left ventricular mass index; LVSV 1 , left ventricular stroke volume index; $\rightarrow$, no effect over time; $\uparrow$, increase over time; $\downarrow$, decrease over time. 

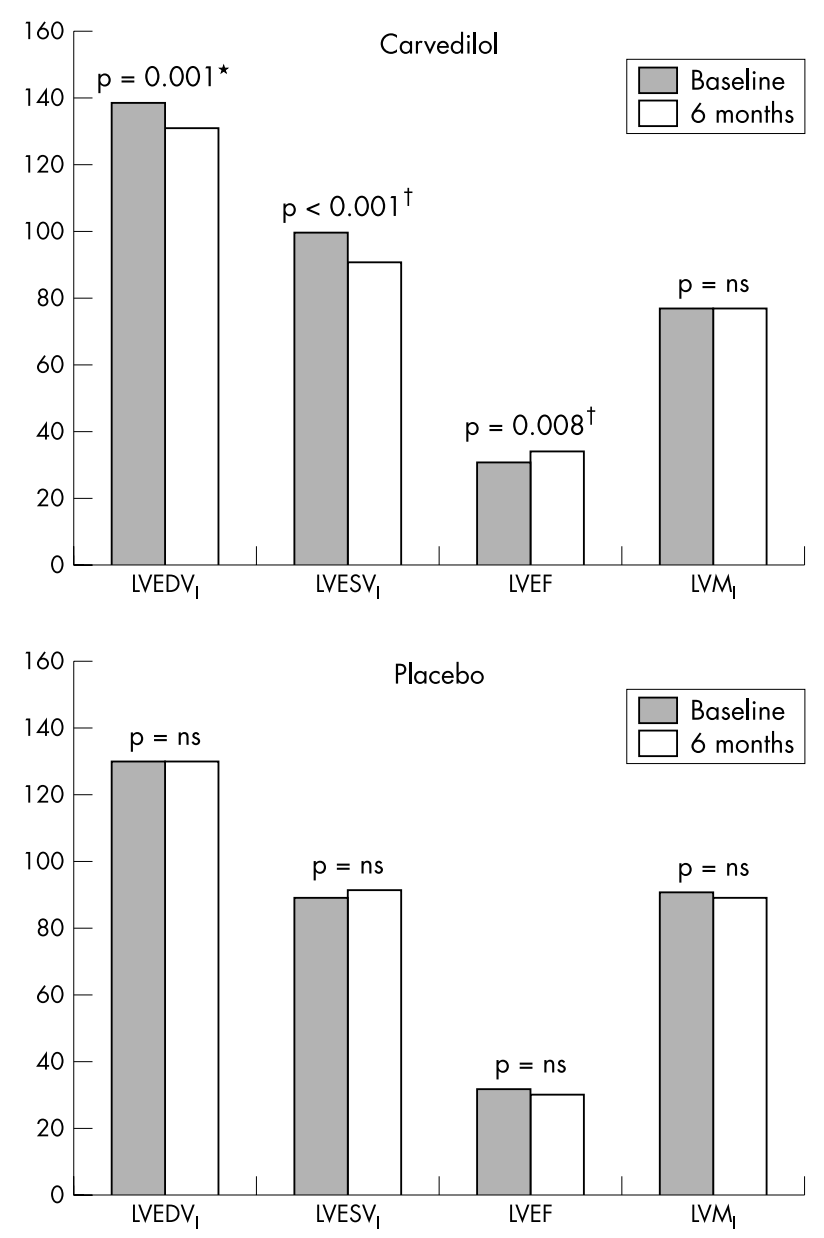

Figure 1 Change in variables over six months. LVEDV $V_{1}$, left ventricular end diastolic volume index; LVESV index; LVEF, left ventricular ejection fraction; $L V M_{1}$, left ventricular mass index. ${ }^{*} p<0.05,+p<0.01$ for the comparison of the change in variable over time between carvedilol and placebo groups.

ESV, $4.8 \%$ for EF, and 3\% for LVM. ${ }^{9}$ The minimum detectable differences in EDV, ESV, EF, and LVM by CMR for the 16 subjects in the carvedilol group were therefore $2.8 \mathrm{ml}, 3.6 \mathrm{ml}$,
6\% (absolute change), and $3.5 \mathrm{~g}$, respectively; for the 13 subjects in the placebo group, the values were $3.2 \mathrm{ml}, 4 \mathrm{ml}$, $6 \%$ (absolute change), and $3.8 \mathrm{~g}$.

\section{RESULTS}

Thirty four patients were recruited into the CMR study and underwent a baseline scan. Of these, five did not complete the study. One patient was withdrawn from the substudy following a possible drug interaction, one because of worsening heart failure, one because of sleep apnoea, and two because of claustrophobia. These patients were therefore excluded from the analysis. All but one of the patients recruited were male. Their mean (SD) age was 71 (8.5) years. Mean $\mathrm{EDV}_{\mathrm{I}}$ was 135 (44) $\mathrm{ml} / \mathrm{m}^{2}$ (normal $66(12) \mathrm{ml} / \mathrm{m}^{2}$ ); mean ESV ${ }_{\mathrm{I}}, 95$ (42) $\mathrm{ml} / \mathrm{m}^{2}$ (normal 21 (8) g/m²); mean EF, 31 (11)\%; and mean $\mathrm{LVM}_{\mathrm{I}}, 83$ (24) g/m² (normal 87 (24) g/ $\mathrm{m}^{2}$ ) (normal values are from Lorenz and colleagues ${ }^{16}$ ). Mean body surface area was $1.84 \mathrm{~m}^{2}$. The groups were well balanced at baseline, with no significant differences between them (table 1). The mean dose of carvedilol achieved in the CMR study patients was 32 (15) $\mathrm{mg}$.

\section{Change over time within each group}

In the carvedilol group, the mean $\mathrm{EDV}_{\mathrm{I}}$ decreased from 139 to $131 \mathrm{ml} / \mathrm{m}^{2}(\mathrm{p}=0.001)$, representing a $5 \%$ decrease over the study period. The $\mathrm{ESV}_{\mathrm{I}}$ decreased by $9 \%$ (from 100 to $91 \mathrm{ml} /$ $\left.\mathrm{m}^{2}, \mathrm{p}=0.0004\right)$, while ejection fraction increased by $9 \%$ (from $31 \%$ to $34 \%, 3 \%$ absolute, $p=0.008$ ). There was no change in $\operatorname{LVSV}_{I}, \mathrm{CO}_{\mathrm{I}}, \mathrm{LVM}_{\mathrm{I}}$, or blood pressure. Within the placebo group there were no significant changes in any of the remodelling indices over time. The changes are summarised in fig 1.

\section{Differences between groups over time}

Over the study period, the carvedilol group showed a reduction in $\mathrm{ESV}_{\mathrm{I}}$ (carvedilol $-9 \mathrm{ml} / \mathrm{m}^{2} v$ placebo $\left.+3, \mathrm{p}=0.0004\right)$. There was also a significant difference in $\operatorname{EDV}_{I}$ (carvedilol $-8 \mathrm{ml} / \mathrm{m}^{2} v$ placebo $\left.0, \mathrm{p}=0.05\right)$ and ejection fraction (carvedilol $+3 \% v$ placebo $-2 \%, p=0.003$ ). None of the other variables differed significantly.

\section{DISCUSSION}

The main finding of this study is that over six months' treatment of chronic stable heart failure, carvedilol resulted in a significant decrease in left ventricular volumes at both

Table 2 Randomised trials of the effect of $\beta$ blocker treatment on ejection fraction

\begin{tabular}{|c|c|c|c|c|c|c|c|}
\hline Study & $\mathbf{n}$ & $\begin{array}{l}\text { Duration } \\
\text { (months) }\end{array}$ & Treatment 1 & EF change* & Treatment 2 & EF change* & $\begin{array}{l}\text { Absolute } \\
\text { difference }\end{array}$ \\
\hline Present study & 34 & 6 & Carvedilol & 8 & Placebo & -2 & 10 \\
\hline Metra $^{44}$ & 34 & 4 & Carvedilol & 10 & Placebo & -1 & 11 \\
\hline Olsen ${ }^{1}$ & 57 & 4 & Carvedilol & 11 & Placebo & 1 & 10 \\
\hline Krum $^{23}$ & 43 & 4 & Carvedilol & 7 & Placebo & 0 & 7 \\
\hline MOCHA study ${ }^{24}$ & 143 & 7 & Carvedilol & 9 & Placebo & 1 & 8 \\
\hline PRECISE study ${ }^{25}$ & 225 & 7 & Carvedilol & 8 & Placebo & 2 & 6 \\
\hline Colucci $^{26}$ & 185 & 7 & Carvedilol & 10 & Placebo & 3 & 7 \\
\hline Cohn $^{27}$ & 55 & 7 & Carvedilol & 9 & Placebo & 2 & 7 \\
\hline ANZ study ${ }^{3}$ & 358 & 12 & Carvedilol & 5 & Placebo & 0 & 5 \\
\hline Guazzi $^{28}$ & 21 & 6 & Carvedilol & 9 & Placebo & -1 & 10 \\
\hline DiLenarda $^{29}$ & 30 & 12 & Carvedilol & 7 & Metoprolol & 0 & 7 \\
\hline Metra $^{22}$ & 122 & 14 & Carvedilol & 11 & Metoprolol & 7 & 4 \\
\hline Kukin $^{6}$ & 53 & 6 & Carvedilol & 6 & Metoprolol & 5 & 1 \\
\hline Sanderson ${ }^{30}$ & 43 & 3 & Carvedilol & 9 & Metoprolol & 6 & 3 \\
\hline Engelmeier $^{31}$ & 24 & 12 & Metoprolol & 6 & Placebo & 4 & 2 \\
\hline MDC study ${ }^{32}$ & 205 & 12 & Metoprolol & 12 & Placebo & 6 & 6 \\
\hline Fisher $^{33}$ & 50 & 6 & Metoprolol & 4 & Placebo & 0 & 4 \\
\hline Goldstein $^{34}$ & 51 & 6 & Metoprolol & 9 & Placebo & 2 & 7 \\
\hline RESOLVD study ${ }^{35}$ & 419 & 6 & Metoprolol & 3 & Placebo & 1 & 2 \\
\hline
\end{tabular}


end systole and end diastole and thereby a reversal of adverse left ventricular remodelling. In addition, the left ventricular ejection fraction improved significantly with carvedilol. Left ventricular volumes and LVEF are strong predictors of all cause mortality and sudden death, ${ }^{17-19}$ and a causal relation is suspected. Despite a reduction in volumes and arterial pressure, which should have reduced left ventricular wall stress, no reduction in left ventricular mass was observed.

An improved mass/volume ratio, leading to a reduction in left ventricular wall stress, could be of benefit either by reducing the metabolic demands on the left ventricle or by reducing the potential for arrhythmias. The sample size used here precludes stratification by dose, but a larger sample and a longer period of follow up could give additional insights into the effect of increasing doses of carvedilol and the duration of treatment on left ventricular remodelling.

Many studies have shown improvement in left ventricular function with $\beta$ blockers (table 2), but the mechanism remains poorly understood. The degree of functional improvement exerted by different agents, as illustrated by a meta-analysis of trials of carvedilol and metoprolol, has led to the suggestion that pharmacological effects other than pure $\beta_{1}$ blockade are responsible. ${ }^{20}$ Indeed, carvedilol significantly reduced mortality compared with metoprolol in the recent COMET study. ${ }^{21}$ Investigators have, however, cautioned that this may simply reflect a lack of equivalence in the $\beta_{1}$ blockers used rather than any additional pharmacological benefits. The exact mechanism of functional improvement has yet to be determined. ${ }^{21}$

Despite the wealth of studies on the effect of $\beta$ blockers on left ventricular function, there have been few previous studies of the effect on left ventricular remodelling. Sharpe and colleagues found a significant reduction in EDV and ESV with carvedilol treatment over 12 months using cross sectional echocardiography in a 123 patient substudy of the Australia/New Zealand heart failure research collaborative group study. ${ }^{36}$ These patients had heart failure of ischaemic origin and were already on an ACE inhibitor. Khattar and colleagues showed a reduction in ESV, but no change in EDV by cross sectional echocardiography with carvedilol monotherapy, and did not find any benefit in ESV when an ACE inhibitor was added to the carvedilol group. ${ }^{37}$ There was, however, a significant reduction in ESV when carvedilol was added in patients who had received six months of ACE inhibitor treatment alone. Groenning and colleagues published a randomised CMR study showing that metoprolol had reverse remodelling effects in 41 patients with chronic heart failure, with a significant reduction in EDVI and ESVI over six months of treatment. ${ }^{38}$ More recently, Dubach and associates used CMR to investigate a placebo controlled trial of bisoprolol in heart failure, but found only a non-significant trend for EDV and ESV reduction over 12 months. ${ }^{39}$ Carvedilol differs from conventional $\beta_{1}$ selective compounds such as metoprolol and bisoprolol in that at therapeutic doses it blocks all three adrenergic receptors $\left(\beta_{1}, \beta_{2}\right.$, and $\left.\alpha_{1}\right)$, resulting in a more comprehensive adrenergic protection of the failing heart. ${ }^{40}$ Furthermore, it reduces cardiac adrenergic activity $^{41}$ and prevents the $\beta_{1}$ receptor upregulation which is typically seen with $\beta 1$ selective agents such as metoprolol. ${ }^{42}$ Because of its $\alpha_{1}$ blocking properties, carvedilol causes moderate peripheral vasodilatation which results in less myocardial depression, no reduction in cardiac output, and no initial haemodynamic compromise (which is normally observed with pure $\beta$ blockers $).{ }^{43}{ }^{44}$ Thus it may be tolerated better than other agents.

\section{Conclusions}

Treatment of chronic stable heart failure with carvedilol results in significant improvement in left ventricular volumes and thereby in reversal of adverse left ventricular remodelling. This may partially explain the benefits of carvedilol on mortality and morbidity in patients with chronic heart failure.

\section{Authors' affiliations}

N G Bellenger, K Rajappan, S L Rahman, J Webster, A J S Coats,

D J Pennell, Royal Brompton Hospital, London, UK

A Lahiri, U Raval, Northwick Park Hospital, London, UK

G D Murray, University of Edinburgh, Edinburgh, UK

J G F Cleland, University of Hull, Hull, UK

\section{REFERENCES}

1 Olsen SL, Gilbert EM, Renlund DG, et al. Carvedilol improves left ventricular function and symptoms in chronic heart failure: a double-blind randomised study. J Am Coll Cardiol 1995;25:1225-31.

2 Packer M, Bristow MR, Cohn JN, et al, for the US carvedilol heart failure study group. The effect of carvedilol on morbidity and mortality in patients with chronic heart failure. N Engl J Med 1996;334:1349-5.

3 Australia/New Zealand Heart Failure research Collaborative Group. Effects of carvedilol in patients with congestive heart failure due to ischaemic heart disease: final results from the ANZ heart failure research collaborative trial. Lancet 1997;349:212-18.

4 Waagstein F, Bristow MR, Swedberg K, et al, for the Metoprolol in Dilated Cardiomyopathy trial Study Group. Beneficial effects of metoprolol in idiopathic dilated cardiomyopathy. Lancet 1993;342:1441-6.

5 CIBIS Investigators and Committees. A randomised trial of B-blockade in heart failure: the cardiac insufficiency bisoprolol study. Circulation 1994;90:1765-73.

6 Kukin ML, Kalman J, Charney RH, et al. Prospective, randomised comparison of effect of long term treatment with metoprolol or carvedilol on symptoms, exercise, ejection fraction and oxidative stress in heart failure. Circulation 1999:99:2645-51.

7 Doughty RN, Whalley GA, Gamble G, et al. Left ventricular remodelling with carvedilol in patients with congestive heart failure due to ischaemic heart disease. Australia-New Zealand heart failure research collaborative group. J Am Coll Cardiol 1997;29:1060-6.

8 Guazzi M, Agostoni P, Matturri M, et al. Pulmonary function, cardiac function, and exercise capacity in a follow-up of patients with congestive heart failure treated with carvedilol. Am Heart J 1999;138:460-7.

9 Bellenger NG, Davies LC, Francis JM, et al. Reduction in sample size for studies of remodelling in heart failure by the use of cardiovascular magnetic resonance. J Cardiovasc Magn Reson 2000;2:271-8.

10 Grothues F, Smith GS, Bellenger NG, et al. Comparison of interstudy reproducibility of cardiovascular magnetic resonance and $2 \mathrm{D}$ echocardiography in normal subjects and in patients with heart failure or left ventricular hypertrophy. Am J Cardiol 2002;90:29-34.

11 Cleland JGF, Pennell DJ, Ray S, et al. Myocardial viability as a determinant of the ejection fraction response to carvedilol in patients with heart failure (CHRISTMAS trial): randomised controlled trial. Lancet 2003;362:14-21

12 Pennell DJ, Ray SG, Davies G, et al. The carvedilol hibernation reversible ischaemia trial, marker of success (CHRISTMAS) study. Methodology of a randomised, placebo controlled, multicentre study of carvedilol in hibernation and heart failure. Int J Cardiol 2000;72:265-74.

13 Bellenger NG, Francis JM, Davies LC, et al. Establishment and performance of a magnetic resonance cardiac function clinic. J Cardiovasc Mag Reson 1999:4:323-30.

14 Katz J, Milliken MC, Stray-Gundersen J, et al. Estimation of human myocardial mass with MR imaging. Radiology 1888;169:495-8.

15 Schwammenthal E, Wichter T, Joachimsen K, et al. Detection of regional left ventricular asynchrony in obstructive hypertrophic cardiomyopathy by magnetic resonance imaging. Am Heart J 1994;127:600-6.

16 Lorenz $\mathrm{CH}$, Walker ES, Morgan VL, et al. Normal human right and left ventricular mass, systolic function and gender differences by cine magnetic resonance imaging. J Cardiovasc Magn Reson 1999;1:7-21.

17 White HD, Norris RM, Brown MA, et al. Left ventricular end-systolic volume as the major determinant of survival after recovery from myocardial infarction. Circulation 1987;76:44-51.

18 McKee PA, Castell WP, Mcnamara PM, et al. The natural history of congestive heart failure: the Framingham study. N Engl J Med 1971;285:1441-5.

19 Ghali JK, Liao Y, Cooper RS. Influence of left ventricular geometric patterns on prognosis in patients with or without coronary artery disease. J Am Coll Cardiol 1998;31:1635-40.

20 Packer M, Antonopoulos GV, Berlin JA, et al. Comparative effects of carvedilol and metoprolol on left ventricular function in heart failure: results of a meta-analysis. Am Heart J 2001;141:884-8

21 Poole-Wilson PA, Swedberg K, Cleland JGF, et al. Comparison of carvedilol and metoprolol on clinical outcomes in patients with chronic heart failure in the carvedilol or metoprolol European trial (COMET): randomised controlled trial. Lancet 2003;362:7-13.

22 Metra ML, Giubbini R, Nodari S, et al. Differential effects of beta blockers in patients with heart failure. A prospective, randomised, double-blind comparison of the long term effects of metoprolol versus carvedilol. Circulation 2000;102:546-51. 
23 Krum H, Sackner-Bernstein JD, Goldsmith RL, et al. Double-blind, placebocontrolled study of the long-term efficacy of carvedilol in patients with severe chronic heart failure. Circulation 1995;92:1499-506.

24 Bristow MR, Gilbert EM, Abraham WT, et al. Carvedilol produces doserelated improvements in left ventricular function and survival in subjects with chronic heart failure. Circulation 1996:94:2807-16.

25 Packer M, Colucci WS, Sackner-Bernstein JD, et al. Double-blind, placebocontrolled study of the effects of carvedilol in patients with moderate to severe heart failure. Circulation 1996;94:2793-9.

26 Colucci WS, Packer M. Bristow MR et al. Carvedilol inhibits clinical progression in patients with mild symptoms of heart failure. Circulation 1996;94:2800-6.

27 Cohn JN, Fowler MB, Bristow MB, et al. Safety and efficacy of carvedilol in severe heart failure. J Card Fail 1997;3:173-9.

28 Guazzi M, Agostoni P, Matturri M, et al. Pulmonary function, cardiac function and exercise capacity in a follow up of patients with congestive cardiac failure treated with carvedilol. Am Heart J 1999;138:460-7.

29 Dilenarda A, Sabbadini G, Salvatore L, et al. Long term effects of carvedilol in idiopathic dilated cardiomyopathy with persistent left ventricular dysfunction despite chronic metoprolol. J Am Coll Cardiol 1999;33:1926-34.

30 Sanderson JE, Chan SKW, Yip G, et al. Beta blockade in heart failure. A comparison of carvedilol with metroprolol. J Am Coll Cardiol 1999;34:1522-8

31 Engelmeimer RS, O'Connell JB, Walsh R, et al. Improvement in symptoms and exercise tolerance by metoprolol in patients with dilated cardiomypathy: a double blind, randomised, placebo controlled trial. Circulation 1985;72:536-46.

32 Waagstein F, Bristow MR, Swedberg K, et al. Beneficial effects of metoprolol in dilated cardiomypathy. Lancet 1993;342:1441-6.

33 Fisher ML, Gottlieb SS, Plotnick GD, et al. Beneficial effects of metoprolol in heart failure associated with coronary artery disease: a randomised trial. J Am Coll Cardiol 1994;23:943-50

34 Goldstein S, Kennedy HL, Hall C, et al. Metoprolol CR/XL in patients with heart failure; a pilot study examining the tolerability, safety, and effect on left ventricular ejection fraction. Am Heart J 1999;138:1158-65.
35 The RESOLVD Investigators. Effects of metoprolol CR in patients with ischaemic and dilated cardiomyopathy. The randomised evaluation of strategies for left ventricular pilot study. Circulation 2000;101:378-84.

36 Sharpe N, Doughty RN. Left ventricular remodelling and improved long-term outcomes in chronic heart failure. Eur Heart $J$ 1998; 19(suppl B):B36-9.

37 Khattar RS, Senior R, Soman P, et al. Regression of left ventricular remodeling in chronic heart failure: Comparative and combined effects of captopril and carvedilol. Am Heart J 2001; 142:704-13.

38 Groenning BA, Nilsson JC, Sondergaard L, et al. Antiremodelling effects on left entricle during beta-blockade with metoprolol in the treatment of chronic heart failure. J Am Coll Cardiol 2000;36:2072-80.

39 Dubach P, Myers J, Bonetti P, et al. Effects of bisoprolol fumarate on left ventricular size, function, and exercise capacity in patients with heart failure: analysis with magnetic resonance myocardial tagging. Am Heart $J$ 2002;143:676-83.

40 Bristow MR. Pathophysiologic and pharmacologic rationales for clinical management of chronic heart failure with beta-blocking agents. Am J Cardiol 1993;71:12-22C

41 Gilbert EM, Abraham AT, Olsen S, et al. Comparative hemodynamic, LV functional, and anti-adrenergic effects of chronic treatment with metoprolol vs carvedilol in the failing heart. Circulation 1996;94:2817-25.

42 Heilbrunn SM, Shah P, Bristow MR, et al. Increased b-receptor density and improved response to catecholamine stimulation during long-term metoprolol therapy in heart failure from dilated cardiomypathy. Circulation 1989;79:483-90

43 Bristow MR, Larrabee P, Muller-Beckmann B, et al. Effects of carvedilol on adrenergic receptor pharmacology in human ventricular myocardium and lymphocytes. Clin Invest 1992;70:S105-13.

44 Metra M, Nardi M, Giubbini R, et al. Effects of short and long term carvedilol administration on rest and exercise haemodynamic variables, exercise capacity and clinical conditions in patients with idiopathic dilated cardiomyopathy. J Am Coll Cardiol 1994;24:1678-87.

\section{IMAGES IN CARDIOLOGY}

\section{Giant left main stem thrombus in a patient with acute coronary syndrome doi: 10.1136/hrt.2003.029165}
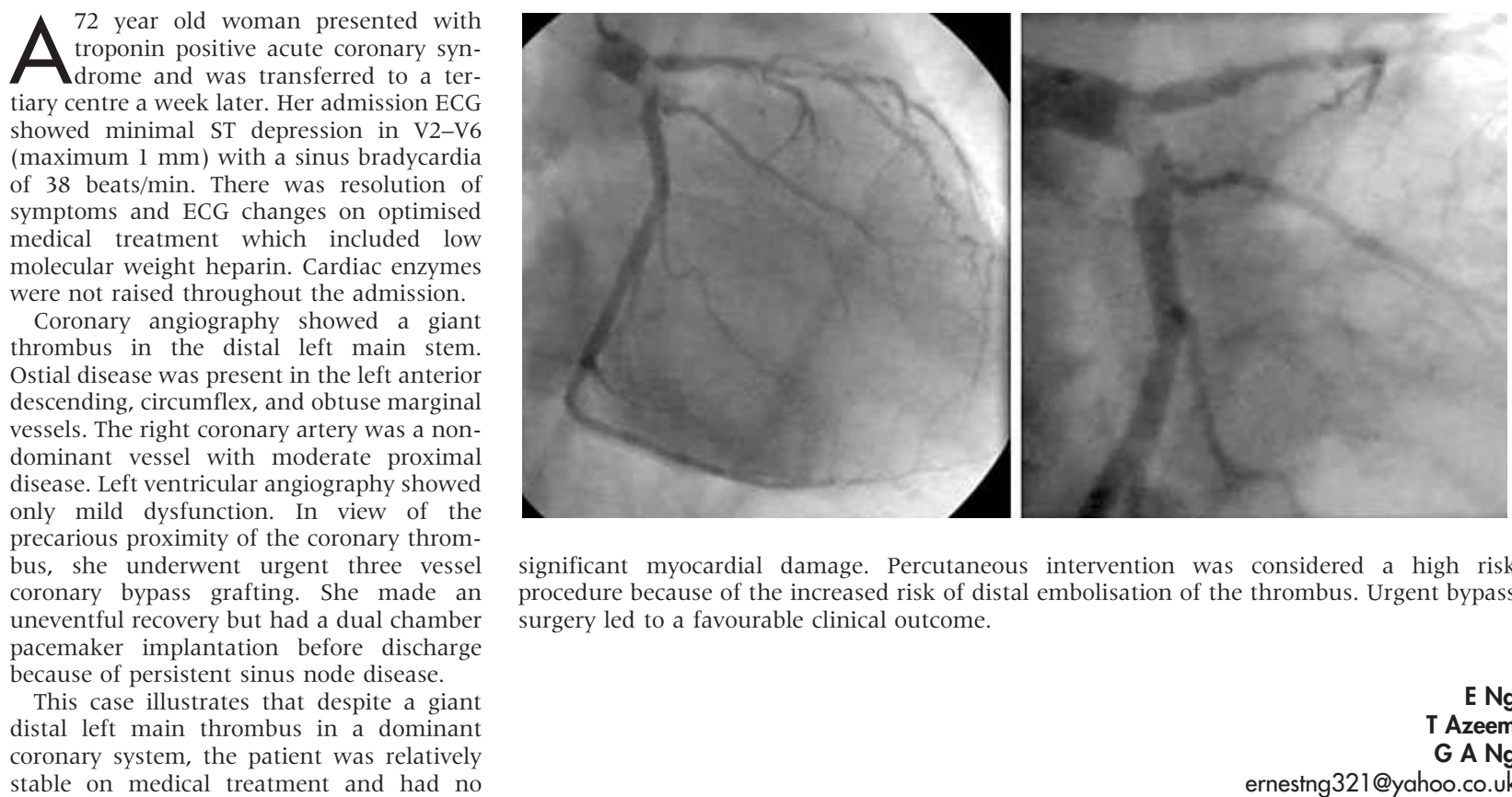

significant myocardial damage. Percutaneous intervention was considered a high risk procedure because of the increased risk of distal embolisation of the thrombus. Urgent bypass surgery led to a favourable clinical outcome. 